\title{
Distanciamentos e aproximações entre a Educação Física escolar e as propostas pedagógicas críticas: o caso da teoria crítico-emancipatória e didática comunicativa
}

\author{
Márcia Morschbacher* \\ Carmen Lúcia da Silva Marques**
}

\begin{abstract}
Resumo: Este artigo objetiva discutir sobre o distanciamento e as possibilidades de aproximação entre a prática pedagógica concreta da escola e as propostas pedagógicas críticas da Educação Física, considerando como referência da discussão a Teoria Crítico-emancipatória e Didática Comunicativa. A argumentação desenvolvida em torno da problemática situase em dois pontos centrais: a necessidade de acesso ao conhecimento produzido e sistematizado referente a essa proposta pedagógica e suas teorias de base; e a superação da dicotomia entre o meio acadêmico e a escola - assentada no fomento de um efetivo diálogo entre ambas as instâncias.

Palavras-chave: Educação física. Ensino. Educação.
\end{abstract}

\section{INTRODUÇÃO}

O panorama atual da Educação Física escolar revela-se um espaço repleto de divergências em relação à sua identidade e à sua especificidade (BRACHT et al, 2005). As temáticas em discussão não se restringem a questões de currículo, métodos de ensino e avaliação: precipuamente, discute-se sobre as bases teóricas a partir das quais esses elementos fundam-se.

'Doutoranda em Educação. Universidade Federal da Bahia. Salvador, BA, Brasil. E-mail: mm.edufisica@yahoo.com.br

"Docente do CEFD/UFSM, Santa Maria, RS, Brasil. E-mail: carminhahidro@yahoo.com.br 
Este cenário apresenta como marco inicial a década de 1980, período de politização do debate da Educação Física em que este componente curricular escolar é arguido quanto à sua estreita relação com os mecanismos reprodutivos capitalistas. Entremeio a críticas e denúncias, o debate suscitado ultrapassa este nível e volta-se às questões relacionadas à prática pedagógica concreta na escola, com a intenção de modificá-la (CAPARROZ; BRACHT, 2007).

Embora o movimento crítico da Educação Física brasileira, ressalvadas as suas diferenças epistemológicas internas, tenha suscitado e contribuído significativamente à produção de conhecimentos relacionados ao ensino desta disciplina no espaço escolar, observa-se uma inquietante antinomia: as suas proposições pedagógicas críticas apresentam incipientes manifestações na prática pedagógica concreta nas escolas - Muniz (1996), Kunz (2006a; 2006b) e Bracht et al. ( 2005) corroboram essa evidência ${ }^{1}$.

Considerando o caso específico da Teoria Crítico-emancipatória e Didática Comunicativa, embora esta proposta pedagógica esteja em discussão e desenvolvimento desde 1991, com a publicação de "Educação Física: ensino \& mudanças" (KUNZ, 1991), e em 1994, com "Transformação didático-pedagógica do esporte" (KUNZ, 1994), além de pesquisas e publicações ${ }^{2}$, esta parece não ter se incorporado à cotidianidade da prática pedagógica em Educação Física escolar, salvo por iniciativas propositivas, em sua maioria, isoladas ${ }^{3}$ (KUNZ, 2006a).

\footnotetext{
${ }^{1} B r a c h t$ (1999) explicita que as propostas pedagógicas adjetivadas como críticas são: a proposta crítico-superadora e a proposta crítico-emancipatória. Essa caracterização advém do fato de que essas se fundamentam e/ou derivam de teorias sociais de cunho crítico. Esclarece-se que não se pretende, neste estudo, empreender um debate epistemológico entre essas propostas, compará-las ou abordá-las como iguais (no sentido de desconsiderar as suas especificidades epistemológicas); trata-se de indicar uma problemática comum a ambas (o seu distanciamento da prática pedagógica concreta) e discuti-la a partir da Teoria Crítico-Emancipatória e Didática Comunicativa, isto é, utilizando-a como suporte teórico-prático da discussão.

${ }^{2}$ À guisa de ilustração, menciona-se o conjunto de obras "Didática da Educação da Educação Física", publicados em três volumes e organizados pelo Professor Elenor Kunz, além de publicações em periódicos e pesquisas.

${ }^{3} \mathrm{~A}$ publicação de Marques, Leal e Morschbacher (2010) representam uma experiência positiva de aproximação dessa proposta pedagógica com a escola.
} 
A partir de tais considerações, este estudo objetivou discutir acerca do distanciamento e das possibilidades de aproximação entre a prática pedagógica cotidiana no contexto da escola e as propostas pedagógicas críticas da Educação Física, considerando especificamente a Teoria Crítico-emancipatória e Didática Comunicativa ${ }^{4}$.

\section{PROCESSO dE CONSTITUIÇÃO dO MOVIMENTO CRÍTICO DA EDUCA- ÇÃo FísICA BRASILEIRA E DA TEORIA CRÍTICO-EMANCIPATÓRIA E DIDÁTI- CA COMUNICATIVA: SUBSÍDIOS INICIAIS}

Nesta seção, considera-se salutar recorrer à história do processo constitutivo do movimento crítico da Educação Física brasileira e da Teoria Crítico-Emancipatória e Didática Comunicativa, na medida em que se entende que esse representa um aspecto elementar ao desenvolvimento ulterior dos propósitos desse trabalho.

Nesse sentido, discorrer acerca de tal processo, cujas origens remetem-se à década de 1980, pressupõe explicitar a trajetória e o papel atribuído à Educação Física a partir da sua inclusão como disciplina curricular obrigatória nas escolas a partir da década de 1930. Indica-se, ademais, a possibilidade de realizar análises acerca dos aspectos que determinam, hodiernamente, a sua prática pedagógica na escola e que necessitam ser superados em função de incumbências pedagógicas outras e precípuas, que transcendem o discurso amplamente veiculado em torno da promoção da aptidão física e da saúde na escola.

A inserção da Educação Física como componente do currículo escolar brasileiro, na década de 1930, referia-se à prática da ginástica na escola (SOARES, 1996). Tal proposta justificava-se pela função

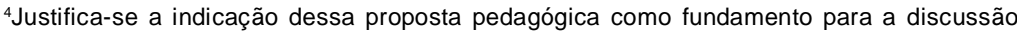
objetivada neste estudo pelo fato de que a problemática em discussão emerge do projeto de extensão intitulado "Possibilidades Integradoras do Atletismo em Aulas de Educação Física: a Proposta Crítico-emancipatória e Didática Comunicativa em Turmas Mistas", no qual a Teoria Crítico-Emancipatória e Didática Comunicativa Ihe serve de base teórica. Tal projeto, cujas atividades iniciaram-se em 2008 e permaneceram em vigência até 2010, pautava-se em aulas de atletismo desenvolvidas por estudantes do curso de Licenciatura em Educação Física de uma Instituição Federal de Ensino Superior em duas escolas públicas.
} 


\section{ArtigosOrignais}

higienista e moralizadora conferida à Educação Física, na medida em que a sua prática possibilitaria o desenvolvimento físico e a promoção da saúde. Ademais, incluíam-se propósitos eugênicos de influência médica e a incumbência de preparar os indivíduos à defesa da nação, cujos influxos provinham da instituição militar. Com a transição de uma sociedade de economia agro-exportadora para urbano-industrial, novas exigências incidiram sobre o seu processo de legitimação na escola: a formação de mão-de-obra apta física e ideologicamente ao trabalho (CASTELLANI FILHO, 2007).

Após a Segunda Guerra Mundial, o esporte adquiriu notoriedade. A Educação Física, por sua vez, foi instrumentalizada de acordo com os códigos deste em sua manifestação de rendimento. Esse processo de "incorporação" não representou um fenômeno isento de contradições, considerando o binômio "esporte na escola" e "esporte $d a$ escola"5: possuía-se, de modo preponderante, o esporte na escola, dimensão em que os valores e princípios intrínsecos ao esporte de rendimento (sobrepujança e comparações objetivas (KUNZ, 2004)) eram reproduzidos na escola e dissimulados a partir do discurso de saúde e educação.

Outro aspecto peculiar à Educação Física no período histórico em questão (década de 1930 até meados da década de 1970, aproximadamente), refere-se às suas teorias de base hegemonicamente, representadas pelas Ciências Naturais e pelas Ciências Biológicas e da Saúde. Tais elementos fundantes eram o arcabouço teórico no qual se legitimava, para essa disciplina na escola, uma prática pedagógica voltada, eminentemente, à promoção da saúde e da aptidão física. Soares $(1996$, p. 6) pondera que, nesse caso, possuía-se um espaço na escola cujo papel não era a de "[...] aprender coisas, coisas que não se sabe ou que, se sabe apenas na superfície", mas treinar/capacitar os sujeitos de acordo com padrões de saúde e performance.

Ao final da década de 1970 e início de 1980, com o processo de "redemocratização" da sociedade brasileira, período em que a

${ }^{5}$ Em referência à expressão de Bracht (1989) e de Vago (1996).

Movimento, Porto Alegre, v. 19, n. 02, p. 149-166, abr/jun de 2013. 
Ditadura Militar, no limiar de sua insuficiência política, cedeu lugar ao modelo político-social tido como democrático, fortaleceram-se os movimentos que manifestavam seu descontentamento em relação ao autoritarismo do governo (CAPARROZ, 1997).

À Educação Física escolar insurgiu um processo de politização do seu debate acadêmico, de modo que esta disciplina curricular passou a ser denunciada e questionada, sobretudo quanto à sua função de legitimação do status quo capitalista (CAPARROZ; BRACHT, 2007).

Este processo ainda foi fomentado pelo incentivo a professores brasileiros para o ingresso em estudos de pós-graduação no exterior e pelos intercâmbios com centros de pesquisa de outros países; além da fundação, no país, de cursos de pós-graduação na área da Educação Física (KUNZ, 2006a).

Ressalva-se, inclusive, que a incursão declarada das Ciências Humanas e Sociais representou certa "reviravolta epistemológica" a essa disciplina curricular, fato que desencadeou o redimensionamento das suas teorias pedagógicas de base, elementos didáticometodológicos e demais aspectos inerentes à sua prática pedagógica.

Esse movimento representou (e representa) um processo peculiar à constituição da Educação Física de modo amplo e, principalmente, da Educação Física escolar, tendo em vista que, inicialmente, passou-se por um período marcado por veementes críticas e denúncias acerca da função social da mesma. Sobretudo a partir de 1990, adentrou-se um segundo momento, marcado pela necessidade de extrapolar este âmbito e voltar-se à transformação da prática pedagógica concreta, visto que, se assim não se procedesse, as críticas esvaziar-se-iam em mero denuncismo (CAPARROZ; BRACHT, 2007).

Ademais, infere-se a ocorrência de certo "amadurecimento" teórico em relação a este debate, considerando que as características iniciais do movimento crítico representaram uma etapa imprescindível à ressignificação da Educação Física mediante referências distintas dos aspectos, até então, preponderantes à sua fundamentação. 
Assim, além das análises que situavam a Educação Física escolar intimamente relacionada a aspectos macrossociais que a conformavam de uma ou outra forma (reprodução dos condicionantes capitalistas e/ou fomento à transformação social), emergem proposições didático-pedagógicas com distintas fundamentações teóricas, entre as quais, as propostas críticas: a crítico-superadora ${ }^{6}$ e a crítico-emancipatória.

Embora não se pretenda analisar cada uma destas propostas pedagógicas - à exceção da segunda - autores, como Muniz (1996), Bracht et al. (2005) e Kunz (2006a), reportam-se a um inquietante distanciamento entre tais proposições e a prática pedagógica concreta. Ora justifica-se esta antinomia a mal-entendidos constituídos acerca destas ${ }^{7}$ (BRACHT, et al., 2005), ora ao agravamento da dicotomia existente entre o meio acadêmico e a escola (KUNZ, 2006a).

Kunz (2006a, p.13), ainda, reporta-se à seguinte antinomia: "a explosão inicial, com perspectivas de uma verdadeira revolução na área", em alusão ao movimento crítico da Educação Física brasileira, parece ter cedido espaço a "certa passividade, conformismo ou pouco interesse em mudanças mais radicais".

Esta questão, qual seja, o distanciamento das propostas pedagógicas (nesse estudo, em específico, da Teoria Críticoemancipatória e Didática Comunicativa), representa a problemática central da discussão proposta a esse trabalho e se encontra desenvolvido nas seções subsequentes.

\section{TeORIAS DE BASE E ASPECTOS DIDÁTICO-PEDAGÓGICOS DA TEORIA Crítico-emancipatória e Didática Comunicativa}

Com a finalidade de subsidiar a discussão em torno da problemática desse estudo e tendo em conta que a Teoria Crítico-

\footnotetext{
${ }^{6}$ Sobre a proposta crítico-superadora, ver Soares et al. (1992).

${ }^{7}$ Bracht $(2005$, p. 47) menciona equívocos, críticas e mal-entendidos imputados às propostas pedagógicas críticas, por exemplo: "[...] secundariza o conteúdo, circunscrevendo-o ao âmbito do discurso; e não condiz com a realidade, por estar distante da prática".
} 
emancipatória e Didática Comunicativa constitui a proposta pedagógica específica na qual se pretende alicerçar o debate perspectivado, objetiva-se, na presente seção, apresentar algumas considerações sobre as suas teorias de base e os seus aspectos didático-pedagógicos.

A Teoria Crítico-emancipatória e Didática Comunicativa tem como elementos teóricos fundantes a Teoria Crítica da Escola de Frankfurt, especialmente no que diz respeito às produções de Jürgen Habermas, no âmbito dos pressupostos relacionados à emancipação humana e à racionalidade comunicativa ${ }^{8}$, e a Fenomenologia, no que alude ao Se-movimentar Humano?.

Essa proposta pedagógica, alicerçada em tais teorias fundantes, engendra consideráveis críticas ao esporte como conteúdo de ensino da Educação Física, pautada no pressuposto de que este é tratado na escola como cópia irrefletida de sua manifestação de rendimento e/ou de performance. Por conseguinte, postula que tal cópia tende a coagir os sujeitos (alunos) à atuação alienada em seu mundo da vida, isto é, reproduzindo os códigos sistêmicos que são característicos tanto a essa manifestação esportiva quanto ao sistema social capitalista (tais como sobrepujança, reificação e/ou alienação, competitividade, subordinação, entre outros) (KUNZ, 2004; 2006b).

Para Kunz (2006b), por outro lado, o esporte pode e/ou deve ser tematizado na escola visando o desenvolvimento dos sujeitos em relação a determinadas competências imprescindíveis à formação

\footnotetext{
${ }^{8}$ Slater (1976 apud FREITAG, 1988) caracteriza a Escola de Frankfurt como um grupo de intelectuais (Theodor W. Adorno, Max Horkheimer, Herbert Marcuse, entre outros, na primeira geração e Jürgen Habermas - entre outros -, na segunda) e a uma teoria social (denominada teoria crítica). Os principais aspectos relacionados a esta Escola, ressalvadas as peculiaridades dos intelectuais que a compõem, situa-se na postura crítica ante a sociedade capitalista e ao pensamento moderno e no resgate do ideal de emancipação humana. Jürgen Habermas, um de seus representantes (e uma das referências da Teoria Crítico-emancipatória e Didática Comunicativa), conforme Freitag (1988), pauta seus estudos na razão comunicativa e atribui ao agir comunicativo caráter emancipatório.

${ }^{9} \mathrm{~A}$ Teoria do Se-movimentar Humano contrapõe-se à compreensão do movimento humano como o de deslocamento de um corpo físico no espaço e no tempo - concepção fundada nas Ciências Naturais (HILDEBRANDT-STRAMANN, 2003). Além disso, compreende o movimento humano como diálogo entre homem e mundo, no qual se inter-relacionam três elementos: o sujeito que se movimenta, a situação (mundo) a que esta ação relaciona-se e os sentidos e significados atribuídos a este diálogo (GORDJIN, 1970 apud KUNZ, 2004).
} 


\section{Artigos Originais}

de sujeitos críticos e emancipados; condição esta que pode subsidiálos no processo de transformação social. Para o autor, uma das questões precípuas colocadas pela Teoria Crítico-emancipatória e Didática Comunicativa é a demanda de:

[...] descobrir que compromisso educacional a encenação pedagógica do esporte deve assumir quando da presença de um educador e no espaço escolar [...] É, na prática, permitir apenas o desenvolvimento de formas de encenação do esporte que são pedagogicamente relevantes (KUNZ, 2006a, p. 73).

Assim, esta proposta pedagógica perspectiva ressignificar a prática pedagógica da Educação Física na escola, atribuindo incumbências e ações didático-metodológicas outras que o mero exercício de habilidades esportivas. Trata-se, portanto, da ampliação dos sentido/significados do esporte e dos demais elementos da cultura de movimento, cuja tematização pedagógica é de incumbência da Educação Física.

O aluno, destarte, deve ter acesso a conhecimentos e experiências que o subsidie a participar na vida social, cultural e esportiva para além da capacidade de praticar o esporte de modo bem-sucedido, segundo suas possibilidades, necessidades e objetivos. Para além disso, há que se oportunizar o desenvolvimento de competências que o permitam: "[...] conhecer, reconhecer e problematizar sentidos e significados nesta vida, a partir da reflexão crítica" (KUNZ, 2006b, p. 31).

A ampliação formativa proposta pela Teoria Críticoemancipatória e Didática Comunicativa pressupõe que a prática pedagógica da Educação Física seja sistematizada a partir das seguintes categorias: trabalho, interação e linguagem. Tais categorias, no decurso do processo de ensino, representam o desenvolvimento das competências objetiva, social e comunicativa, respectivamente.

A competência objetiva refere-se aos conhecimentos, informações e experiências de movimento que permitam ao sujeito 
agir de modo competente e bem-sucedido nas suas ações do semovimentar humano (KUNZ, 2006b). Fundamentado na "concepção fenomenológica do se-movimentar humano", que concebe o semovimentar como um diálogo entre homem e mundo em que existe um sujeito que se movimenta, uma situação (mundo) e sentidos/ significados relacionados este diálogo (GORDJIN, 1970 apud KUNZ, 2004), Kunz (2004; 2006b) utiliza-se da proposta de Gordjin (1975 apud KUNZ, 2004) e de Tamboer (1985 apud KUNZ, 2004) para explicitar o processo de aquisição de "um Mundo de significados motores" intencionado com o desenvolvimento da competência objetiva. Tal processo é delineado em três etapas denominadas "Transcendência de Limites", sobre as quais se discorre a seguir.

A "Transcendência de Limites pela Forma Direta" compreende a experimentação direta e não problematizada do mundo em que o sujeito atribui sentidos/significados ao seu se-movimentar a partir do seu mundo vivido e da situação colocada pela ação do movimento. A "Transcendência de Limites pela Forma Aprendida" referencia a aprendizagem dos elementos objetivos a partir da intencionalidade constituída pela ideia ou imagem do movimento. Nesta etapa, prescinde-se de um processo de ensino de destrezas impostas e padronizadas e possibilita-se a problematização, a reflexão, a busca e a construção de possibilidades de se-movimentar (KUNZ, 2004). A "Transcendência de Limites pela Forma Criativa-inventiva" abrange a criação e recriação de movimentos em consonância com uma dada situação. Aqui, a partir das duas formas anteriores, ressalta-se o processo de "constituição e exploração de novos sentidos/ significados" pelos sujeitos (MOLLENHAUER, 1972 apud KUNZ, 2004).

A competência social, expressa pela categoria interação, diz respeito às experiências em interações sociais com base no agir solidário, cooperativo e participativo (MAYER, 1987 apud KUNZ, 2006b) e compreende, sobretudo, um processo de problematização e de ressignificação das relações e dos papéis sociais marcados 
pela discriminação e pela sobrepujança. Essa competência deve contribuir ao agir solidário e cooperativo e suscitar a compreensão acerca dos diferentes papéis sociais existentes no esporte e socialmente, assim como capacitar os sujeitos a assumirem determinados papéis e compreender os outros neste processo (KUNZ, 2006b).

À consecução das demandas colocadas pela Teoria Críticoemancipatória e Didática Comunicativa consubstanciam-se mediante uma prática pedagógica fundamentada na Didática Comunicativa. Para tanto, o desenvolvimento da competência comunicativa, além de imprescindível ao decurso da prática pedagógica, é elemento fundamental aos intentos formativos de sujeitos críticos e emancipados. Essa competência abrange tanto a linguagem (diálogo realizado a partir de palavras) quanto o se-movimentar humano (já aludido no decurso desta seção).

No caso da linguagem, baseando-se nos fundamentos da razão comunicativa, o diálogo engendrado pelos sujeitos para alcançar entendimentos relacionados às situações de aprendizagem, a ação de expressar-se e interpretar experiências individuais e coletivas e a compreensão do que os demais comunicam desencadeiam iniciativas do pensamento crítico (KUNZ, 2006b).

\section{Distanciamentos e aproximações entre a Educação Físıca Escolar e a Teoria Crítico-emancipatória e Didática Comuni- CATIVA: CONSTITUINDO POSSIBILIDADES SUPERADORAS}

Tendo em vista a problemática elencada para discussão neste artigo e as questões já arroladas nas suas etapas anteriores, esta seção objetiva ponderar sobre o distanciamento e as possibilidades de aproximação entre a prática pedagógica e as propostas pedagógicas críticas da Educação Física, considerando a Teoria Crítico-emancipatória e Didática Comunicativa. Sistematizou-se tal discussão, nesse ínterim, a partir de dois pontos principais: necessidade de acesso ao conhecimento produzido e sistematizado 
referente a essa proposta pedagógica e suas teorias de base e; a superação da dicotomia entre o meio acadêmico e a escola ${ }^{10}$.

Retomando a argumentação de Bracht et al. (2005), no tocante aos equívocos imputados às propostas pedagógicas críticas, considerase que uma das possibilidades de superar o distanciamento e potencializar a aproximação dessas proposições (em específico, a Teoria Crítico-emancipatória e Didática Comunicativa) à prática pedagógica concreta da Educação Física na escola se relaciona com o oferecimento de condições para uma sólida formação teórica dos professores.

Nesse sentido, considera-se que transformações efetivas na prática pedagógica dessa disciplina escolar podem ser fomentadas a partir da promoção de condições e de possibilidades, sobretudo nos cursos de formação em Educação Física, para que os estudantes e professores tenham acesso ao conhecimento referente à proposta pedagógica em questão e às suas teorias de base, anteriormente aludidas - o mesmo deve ser considerado e/ou estendido, a todas as proposições pedagógicas reconhecidas na área da Educação e da Educação Física.

Contrariamente ao "esvaziamento teórico" e/ou ao "praticismo inconsequente", apresentados como tendências na formação de professores de Educação Física e legitimados, inclusive, pelos próprios ordenamentos legais que a regulam hodiernamente ${ }^{11}$, salienta-se aqui a importância da articulação entre teoria e prática. Trata-se de conferir centralidade à premissa a partir da qual se

\footnotetext{
${ }^{10} \mathrm{Ao}$ mencionarem-se esses dois aspectos, não se desconsideram, todavia, as condições objetivas que determinam a forma como a prática pedagógica da Educação Física ocorre na escola, tais como as condições físicas e materiais, as políticas educacionais, as condições de trabalho dos professores, entre outros elementos.

${ }^{11}$ No tocante a esse aspecto, uma das principais críticas sustentada acerca desses ordenamentos legais (denominados Diretrizes Curriculares Nacionais - Resolução CNE/CP 01/2002 e Resolução CNE/CES 07/2004) se refere à referência indicada como concepção nuclear dos cursos de graduação em Educação Física (e demais cursos de licenciatura - no caso da primeira resolução), qual seja, o desenvolvimento de competências (BRASIL, 2002; 2004). Concebidas como a capacidade de mobilizar conhecimento em ação, tal referência enfatiza o "saber-fazer", a resolução de problemas imediatos da ação pedagógica e subsume o conhecimento (teórico) a essa dimensão. A esse respeito, também ver os estudos de Duarte $(2001 ; 2003)$.
} 
concebe que a teoria sustenta a prática pedagógica e que esta, por sua vez, sustenta e possibilita o avanço da teoria. Além do fato de que a cisão dessas duas "dimensões" tende, ora ao teoricismo, ora ao praticismo.

No bojo desta discussão, aponta-se que, não raras ocasiões, as questões relativas ao "o quê ensinar" e ao "como ensinar" adquirem considerável centralidade no que se refere ao processo de formação dos estudantes dos cursos superiores de Educação Física, em detrimento do que Kunz (2006a) aponta como as respostas à pergunta "Educação Física, para quê?". Consoante esse autor, a(s) resposta(s) a essa pergunta necessitam preceder, bem como fundamentar, às respostas aos dois elementos supracitados - "o quê" e "como ensinar".

Nesse sentido, há que se atentar para o estudo dos "temas fundamentais" que fundam a prática pedagógica da Educação Física na escola (KUNZ, 1998; 2004; 2006b). Tais "temas fundamentais" (concepções relativas a corpo, movimento, cultura de movimento, ensino, educação, escola, dentre outros (KUNZ, 1998)), constituem os conceitos basilares dessa disciplina escolar e necessitam ser apreendidos pelo professor de modo consistente. Além dos "temas fundamentais", enuncia-se a importância de que a(s) proposta(s) pedagógica(s) seja(m) abordadas em seus elementos constituintes, relacionados na prática pedagógica tanto de forma mediata (pressupostos teóricos e teorias de base) quanto imediata (elementos didático-pedagógicos: objetivos, conteúdos de ensino, "etapas" e estratégias de ensino, entre outros) como possibilidade para potencializar a superação do estado de coisas aqui problematizado.

Sustenta-se, ainda, que o estabelecimento de parâmetros sólidos quanto à função social da educação, da escola, da Educação Física e de suas propostas pedagógicas podem contribuir para a superação da problemática central desta discussão. Assim, o constante estudo e discussão em torno desses pontos necessitam, portanto, servir de ponto de partida e de chegada à formação dos professores de Educação Física e à sua prática pedagógica. 
A outra questão enunciada para a discussão, diz respeito à necessidade de suplantar a dicotomia comumente evidenciada entre o meio acadêmico e a escola. Argui-se, destarte, em prol do trabalho colaborativo entre ambas as instâncias, em detrimento de hierarquias e/ou da separação entre instituições que produzem conhecimento (por suposto, as instituições de ensino superior) e instituições que "aplicam-no" (neste caso, a escola).

Kunz (2006a) considera que, em específico sobre este ponto em discussão, se produziu uma "enorme lacuna" entre a produção do conhecimento, sobretudo relativo ao desenvolvimento de pressupostos teórico-metodológicos da Educação Física com referência nas áreas humanas e sociais e a Educação Física em sua concretude no espaço escolar.

Esse autor aponta também sobre a eminente necessidade de que o diálogo entre as instâncias supracitadas seja retomado e intensificado, a exemplo do que ocorreu no decurso da década de 1980, período no qual: "Havia diálogo entre atores teóricos das academias universitárias com atores empíricos, dos profissionais que atuavam na prática com a Educação Física em seus diferentes contextos [...] O diálogo continua, [...] mas em um círculo muito

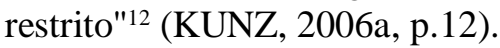

No que diz respeito às instituições de ensino superior ${ }^{13}$, tratase de materializar o diálogo com o espaço escolar fundado na indissociabilidade entre ensino, pesquisa e extensão - propondo ações factíveis ao considerar-se o âmbito da produção de conhecimento (pesquisa), do desenvolvimento de propostas (ensino) e de ações efetivas (extensão) na escola.

\footnotetext{
${ }^{12}$ Kunz (2006a) relata ainda que: "Na década de 1980 [...] era evidente o esforço de um enorme contingente de profissionais atuantes fora do contexto das academias, dos pensadores e pesquisadores, mas na escola, na academia, nas escolinhas, que se esforçavam em participar ativamente do processo de evolução da área".

${ }^{13} T e n d o$ em conta as diferentes instituições destinadas à formação superior no país (universidades, centros universitários, faculdades, institutos superiores de educação, entre outras), ressalta-se que somente às universidades se coloca como demanda atividades de ensino, pesquisa e extensão. Às demais, em geral, as exigências no tocante a esses aspectos é menor, a ponto de algumas instituições dedicarem-se, predominantemente, às atividades de ensino.
} 
Tais ações necessitam alicerçar-se, bem como provir da função social atribuída à essas instituições, colocada, indubitavelmente, para além do cumprimento de demandas institucionais e de produção acadêmica $^{14}$. Isto significa que essa função social e as ações engendradas em torno desta, principalmente a partir da indissociabilidade dos seus três elementos basilares (pesquisa, ensino e extensão), necessitam manifestar-se efetivamente, no sentido de transcender o tensionamento que tem caracterizado algumas relações entre a universidade e a escola.

À escola, por sua vez, atribui-se que, neste diálogo, o compartilhamento de experiências e de conhecimento produzido na e pela prática pedagógica concreta pode e deve ser uma das questões fulcrais. Entende-se que a mesma representa um espaço cujas possibilidades de aproximação da prática pedagógica concreta das propostas pedagógicas críticas coloca-se de modo potencial. No entanto, estas possibilidades demandam, além do comprometimento sócio-político dos professores de Educação Física no sentido de transformar a sua prática pedagógica com base em pressupostos críticos, que tanto as escolas quanto as universidades empreendam ações efetivas no sentido de potencializar o processo de aproximação (interlocução) entre as duas instâncias.

Nesse ínterim, evidencia-se como demanda a elaboração e implementação de políticas institucionais nas quais se intensifique o diálogo entre as instituições de ensino superior e a instituição escolar. Há que se viabilizar, ressalta-se, um efetivo diálogo, em que a interação ocorra mediante relações de colaboração e de

\footnotetext{
${ }^{14}$ Anísio Teixeira (1998) indica quatro dimensões ou função principais atribuídas à universidade: função profissional, "alargamento da mente humana" com o contato com o saber e a sua busca, desenvolvimento do saber humano (a universidade não somente difunde o conhecimento, como também o produz) e transmissão de uma cultura comum. Ainda conforme o autor: "A função da universidade é uma função única e exclusiva. Não se trata somente de difundir conhecimentos. [...] Não se trata, somente, de conservar a experiência humana. [...] Não se trata, somente, de preparar práticos ou profissionais, de ofícios ou artes. [...] Trata-se de manter uma atmosfera de saber para se preparar o homem que o serve e o desenvolve. Tratase de conservar o saber vivo e não morto, nos livros ou no empirismo das práticas não intelectualizadas. Trata-se de formular intelectualmente a experiência humana, sempre renovada, para que a mesma se torne consciente e progressiva" (TEIXEIRA, 1998, p. 35).
} 
reciprocidade e que o conhecimento advindo e produzido em ambas e por ambas sirva-lhes de base consistente para ações e transformações efetivas na realidade concreta.

\section{Considerações finaIS}

Ressalvados os propósitos elencados para este artigo, reiterase o posicionamento de que a superação do distanciamento evidenciado entre as propostas pedagógicas críticas da Educação Física e a prática pedagógica concreta desta disciplina escolar encontra-se, entre outras questões, na necessidade de "retorno" e/ ou "ida" ao estudo dessas proposições e de suas teorias de base e na ressignificação do diálogo entre o meio acadêmico e a escola.

Esses dois pontos, situados aquém da pretensão de esgotar a discussão acerca desta problemática, representam possibilidades e/ ou apontamentos, com os quais se intenta suscitar o debate e alinharse àqueles que, desde a década de 1980, inquirem e intervêm na prática pedagógica da Educação Física a partir de fundamentos outros que as referências hegemônicas dessa área. 


\begin{abstract}
Distance and approaches between the Physical Education and the critical pedagogical proposals: the case of Theory CriticalEmancipatory and Communicative Didacticism Abstract: This article aims to discuss about the distance and approach possibilities between school pedagogical practice and pedagogical critical propositions of Physical Education, taking as reference the discussion the Theory Critical-Emancipatory and Communicative Didacticism. The arguments have two focal points: the need for access to produced and systematized knowledge about this pedagogical proposition and their underlying theories; and to overcome the dichotomy between the academic and school - founded in promoting an effective dialogue between the two.
\end{abstract}

Keywords: Physical Education. Teaching. Education.

\begin{abstract}
Las distancias y aproximaciones entre la educación física y las propuestas pedagógicas críticas: el caso de la Teoría CríticaEmancipadora y Didáctica Comunicativa

Resumen: Este artículo tiene como objetivo discutir la distancia y las posibilidades de aproximaciones entre la práctica pedagógica de la escuela e y las propuestas pedagógicas críticas de la Educación Física, teniendo como referencia la discusión la Teoría CríticaEmancipadora y Didáctica Comunicativa. Los argumentos en torno a la cuestión radica en dos puntos principales: la necesidad de acceder al conocimiento producido y sistematizado sobre este propuesta pedagógica y sus teorías subyacentes; y superar la dicotomía entre lo académico y en la escuela basado en el desarrollo de un diálogo efectivo entre los dos. Palabras-clave: Educación Física. Enseñanza. Educación.
\end{abstract}

\title{
REFERÊNCIAS
}

BRACHT, Valter. Educação física: a busca da autonomia pedagógica. Revista da Fundação de Esporte e Turismo, Curitiba, v. 1, n. 2, p. 12-19, 1989. Disponível em: < http://www.boletimef.org/biblioteca/2350/Educacao-Fisica-a-busca-daautonomia-pedagogica>. Acesso em: 29 jun. 2009.

A constituição das teorias pedagógicas da educação física. Caderno CEDES, Campinas, v. 19, n. 48, 1999. Disponível em: <http://www.scielo.br/ scielo.php?pid=S0101-32621999000100005\&script=sci_arttext\&tlng=pt >. Acesso em: 13 maio 2008. 
Esporte na escola e esporte de rendimento. Movimento, Porto Alegre, v. 7, n. 12, p. XIV-XIX, 2000.

BRACHT, Valter et al. Pesquisa em ação: educação física na escola. 2. ed. ljuí: Unijuí, 2005.

BRASIL. Conselho Nacional de Educação. Câmara de Educação Superior. Resolução CNE/CES 07/2004, de 31 de março de 2004. Institui as Diretrizes Curriculares Nacionais para os cursos de graduação em Educação Física, em nível superior de graduação plena. Brasília, 2004. Disponível em: <http://portal.mec.gov.br/ cne/arquivos/pdf/ces0704edfisica.pdf>. Acesso em: 27 ago. 2010.

Conselho Nacional de Educação. Conselho Pleno. Resolução CNE/CP 01/2002, de 18 de fevereiro de 2002. Institui as Diretrizes Curriculares Nacionais para a Formação de Professores da Educação Básica, em nível superior, curso de licenciatura, de graduação plena. Brasília, 2002. Disponível em: <http:// portal.mec.gov.br/cne/arquivos/pdf/rcp01_02.pdf>. Acesso em: 27 ago. 2010.

CAPARROZ, Francisco Eduardo. Entre a educação física na escola e a educação da escola: a educação física como componente curricular. Vitória: UFES, Centro de Educação Física e Desportos, 1997.

CAPARROZ, Francisco Eduardo; BRACHT, Valter. O tempo e o lugar de uma didática da educação física. Revista Brasileira de Ciências do Esporte, Campinas, v. 28, n. 2, p. 21-37, jan. 2007.

CASTELLANI FILHO, Lino. Educação física no Brasil: a história que não se conta. 14. ed. Campinas: Papirus, 2007.

DUARTE, Newton. As pedagogias do "aprender a aprender" e algumas ilusões da assim chamada sociedade do conhecimento. Revista Brasileira de Educação, Rio de Janeiro, n. 18, p. 35-40, 2001.

. Conhecimento tácito e conhecimento escolar na formação do professor (por que Donald Schön não entendeu Luria). Educação \& Sociedade, Campinas, v. 24 , n. 83 , p. 601-625, ago. 2003.

FREITAG, Bárbara. A teoria crítica: ontem e hoje. 2. ed. São Paulo: Brasiliense, 1988.

HILDEBRANDT-STRAMANN, Reiner. Textos pedagógicos sobre o ensino da educação física. 2. ed. ljuí: Unijuí, 2003.

KUNZ, Elenor. Educação Física: ensino e mudanças. Ijuí: Unijuí, 1991.

3.ed. ljuí: Unijuí, 2004.

Educação física escolar: seu desenvolvimento, problemas e propostas. In:SEMINÁRIOBRASILEIROEM PEDAGOGIA DOESPORTE: FUNÇÕES, TENDÊNCIAS E PROPOSTAS PARAA EDUCAÇÃO FÍSICA ESCOLAR, 1998, Santa Maria. Anais... Santa Maria: CEFD-UFSM, 1998. p. 114-119. 


\section{ArtigosOriginais Márcia Morschbacher, Carmen Marques}

Pedagogia do esporte, do movimento humano ou da educação física? In: KUNZ, Elenor; TREBELS, Andreas (Org.). Educação física crítico-emancipatória com uma perspectiva da pedagogia alemã do esporte. ljuí: Unijuí, 2006a.

Transformação didático-pedagógica do esporte. ljuí: Unijuí, 1994. 7.ed. ljuí: Unijuí, 2006b.

KUNZ, Elenor; SOUZA, Maristela da Silva. Unidade didática 1: atletismo. In: KUNZ, Elenor (Org.). Didática da educação física 1. 4. ed. Ijuí: Unijuí, 2006.

MARQUES, Carmen Lúcia da Silva; LEAL, Matiele Bueno; MORSCHBACHER, Márcia. Possibilidades integradoras do atletismo em aulas de Educação Física e a Teoria Crítico-Emancipatória e Didática Comunicativa: fragmentos de uma experiência na escola. Cadernos de Formação RBCE, Campinasm, p. 84-95, 2010.

MUNIZ, Neyse Luz. Influências do pensamento pedagógico renovador da educação física: sonho ou realidade? 1996. Dissertação (Mestrado em Educação Física) - Universidade Gama Filho, Rio de Janeiro, 1996.

SOARES, Carmen Lúcia. Educação física escolar: conhecimento e especificidade. Revista Paulista de Educação Física, São Paulo, supl. 2, p. 6-12, 1996.

SOARES, Carmen Lúcia et al. Metodologia do ensino de educação física. São Paulo: Cortez, 1992.

TEIXEIRA, Anísio. Educação e universidade. Rio de Janeiro: UFRJ, 1998.

VAGO, Tarcísio Mauro. O "esporte na escola" e o "esporte da escola": da negação radical para uma relação de tensão permanente. Movimento, Porto Alegre, v. 3, n.5, p. 4-17, 1996.

Endereço para correspondência:

Carmen Lucia da Silva Marques

Rua Venancio Aires, 701. Centro. Santa Maria. RS.

cp-97010-001.

Recebido em: 03.06.2012

Aprovado em: 18.01.2013

ovimento, Porto Alegre, v. 19, n. 02, p. 149-166, abr/jun de 2013. 